The University of Southern Mississippi

The Aquila Digital Community

Faculty Publications

$2-1-2013$

\title{
The Relative and Unique Contributions of Emotion Dysregulation and Impulsivity to Posttraumatic Stress Disorder Among Substance Dependent Inpatients
}

\author{
Nicole H. Weiss \\ Jackson State University \\ Matthew T. Tull \\ University of Mississippi Medical Center \\ Michael D. Anestis \\ University of Southern Mississippi, mda141@sph.rutgers.edu \\ Kim L. Gratz \\ University of Mississippi Medical Center
}

Follow this and additional works at: https://aquila.usm.edu/fac_pubs

Part of the Psychology Commons

\section{Recommended Citation}

Weiss, N. H., Tull, M. T., Anestis, M. D., Gratz, K. L. (2013). The Relative and Unique Contributions of Emotion Dysregulation and Impulsivity to Posttraumatic Stress Disorder Among Substance Dependent Inpatients. Drug and Alcohol Dependence, 128(1), 45-51.

Available at: https://aquila.usm.edu/fac_pubs/17098

This Article is brought to you for free and open access by The Aquila Digital Community. It has been accepted for inclusion in Faculty Publications by an authorized administrator of The Aquila Digital Community. For more information, please contact Joshua.Cromwell@usm.edu. 


\title{
The Relative and Unique Contributions of Emotion Dysregulation and Impulsivity to Posttraumatic Stress Disorder among Substance Dependent Inpatients
}

\author{
Nicole H. Weiss, \\ Jackson State University Department of Psychology 1325 J.R. Lynch Street Jackson, Mississippi, \\ USA, 39217
}

Matthew T. Tull*, University of Mississippi Medical Center Department of Psychiatry and Human Behavior 2500 North State Street Jackson, Mississippi, USA, 39216

Michael D. Anestis, and Florida State University Department of Psychology 1107 West Call Street Tallahassee, Florida, USA, 32306

Kim L. Gratz University of Mississippi Medical Center Department of Psychiatry and Human Behavior 2500 North State Street Jackson, Mississippi, USA, 39216

\section{Abstract}

BACKGROUND—Despite elevated rates of posttraumatic stress disorder (PTSD) among substance use disorder (SUD) patients, as well as the clinical relevance of this co-occurrence, few studies have examined psychological factors associated with a PTSD-SUD diagnosis. Two factors worth investigating are emotion dysregulation and impulsivity, both of which are associated with PTSD and SUDs. Therefore, this study examined associations between PTSD and facets of emotion dysregulation and impulsivity within a sample of trauma-exposed SUD inpatients.

\begin{abstract}
METHODS-Participants were an ethnically diverse sample of 205 SUD patients in residential substance abuse treatment. Patients were administered diagnostic interviews and completed a series of questionnaires.
\end{abstract}

RESULTS-Patients with PTSD $(n=58)$ reported significantly higher levels of negative urgency (i.e., the tendency to engage in impulsive behaviors when experiencing negative affect) and lower sensation seeking, as well as higher levels of emotion dysregulation and the specific dimensions of lack of emotional acceptance, difficulties engaging in goal-directed behavior when upset,

\footnotetext{
(C) 2012 Elsevier Ireland Ltd. All rights reserved.

*Address correspondence to Matthew T. Tull, Department of Psychiatry and Human Behavior, University of Mississippi Medical Center, Jackson, Mississippi 39216, Voice: 601-815-6518. Fax: 601-984-4489. MTull@umc.edu..

Publisher's Disclaimer: This is a PDF file of an unedited manuscript that has been accepted for publication. As a service to our customers we are providing this early version of the manuscript. The manuscript will undergo copyediting, typesetting, and review of the resulting proof before it is published in its final citable form. Please note that during the production process errors may be discovered which could affect the content, and all legal disclaimers that apply to the journal pertain.

Conflict of Interest

The authors have no conflicts of interest to declare.

Contributors

Author NHW and MTT designed the study. NHW and MDA wrote the first draft of the manuscript and completed statistical analyses. MTT and KLG assisted in the completion of the final manuscript. All authors contributed to addressing reviewer comments. All authors contributed to and have approved the final manuscript.
} 
difficulties controlling impulsive behaviors when distressed, limited access to effective emotion regulation strategies, and lack of emotional clarity. Further, overall emotion dysregulation emerged as a significant predictor of PTSD status, accounting for unique variance in PTSD status above and beyond facets of impulsivity (as well as other relevant covariates).

CONCLUSIONS-Results suggest that emotion dysregulation may contribute to the development, maintenance, and/or exacerbation of PTSD and highlight the potential clinical utility of targeting emotion dysregulation among SUD patients with PTSD.

\section{Keywords}

emotion; emotion regulation; impulsivity; posttraumatic stress disorder; traumatic exposure; substance use disorders

\section{INTRODUCTION}

Posttraumatic stress disorder (PTSD) is characterized by re-experiencing, avoidance, emotional numbing, and hyperarousal symptoms following exposure to a traumatic event (American Psychiatric Association, 2000). The lifetime prevalence of PTSD in the general population is 6.8\% (Kessler et al., 2005); however, heightened lifetime (36-50\%) and current (25-42\%) prevalence rates of PTSD have been found among patients with a substance use disorder (SUD; Brady et al., 2004a). A PTSD-SUD diagnosis is associated with a range of negative clinical outcomes and maladaptive behaviors, including greater risk for SUD treatment dropout (Brady, 2001; Ford et al., 2007), quicker relapse following SUD treatment (Hien et al., 2000; Najavits et al., 2007), more severe substance use patterns within community (Cottler et al., 1992) and treatment-seeking (Najavits et al., 2007) samples, and higher rates of risky and self-destructive behaviors among patient (Najavits et al., 2007) and community (Plotzker et al., 2007) samples. Despite this, few studies have examined the psychological factors associated with a PTSD-SUD diagnosis. Two factors worth investigating are emotion dysregulation and impulsivity, both of which are associated with PTSD (e.g., Kotler et al., 2001; Tull et al., 2007) and heightened among SUD patient (Fox et al., 2007, 2008; Moeller and Dougherty, 2002; Patton et al., 1995) and community (Allen et al., 1998; Patton et al., 1995) samples.

Emotion dysregulation is a multi-faceted construct involving: (a) a lack of awareness, understanding, and acceptance of emotions; (b) the inability to control behaviors when experiencing emotional distress; (c) a lack of access to adaptive strategies for modulating the duration and/or intensity of aversive emotional experiences; and (d) an unwillingness to experience emotional distress as part of pursuing meaningful activities in life (Gratz and Roemer, 2004). Previous studies using non-clinical or community samples have found that PTSD symptom severity is associated with overall emotion dysregulation and the specific dimensions of lack of emotional acceptance, difficulties engaging in goal-directed behavior and controlling impulsive behavior when upset, limited access to emotion regulation strategies, and lack of emotional clarity (Ehring and Quack, 2010; Tull et al., 2007). Similar associations were observed among cocaine dependent patients in residential SUD treatment (McDermott et al., 2009).

Theoretical literature also highlights the role of emotion dysregulation in the development and maintenance of PTSD among individuals with a SUD. Consistent with negative reinforcement (Baker et al., 2004) and self-medication (Brady et al., 2004a) models of substance abuse, substances may be used to manage PTSD-related symptoms and associated distress following a traumatic event. The use of this particular maladaptive emotion regulation strategy may be more likely among individuals with a SUD. In addition to having 
familiarity with and access to substances, individuals with (vs. without) a SUD have been found to exhibit higher overall emotion dysregulation (Fox et al., 2007, 2008). Notably, however, although substance use may result in the immediate (short-term) reduction of PTSD-related symptoms and emotional distress, it is likely to have paradoxical consequences in the long-term, preventing exposure to corrective information and interfering with emotional processing (Foa and Kozak, 1986). Thus, using substances to regulate emotions will likely exacerbate PTSD symptoms and emotion dysregulation in the long-term, increasing motivations to use substances as an avoidant regulation strategy (Hayes et al., 1996).

Research also provides preliminary support for an association between impulsivity and PTSD. Although several definitions for impulsivity have been proposed (Cloninger et al., 1993; Eysenck and Eysenck, 1977), recent literature suggests that impulsivity is best defined as a multi-faceted construct consisting of four dimensions: (a) Urgency (the tendency to act impulsively when experiencing negative affect); (b) (lack of) Premeditation (failure to reflect on the consequences of an act before engaging in that act); (c) (lack of) Perseverance (an inability to focus or follow through on difficult or boring tasks); and (d) Sensation Seeking (the tendency to enjoy and pursue activities that are exciting and an openness to trying new experiences; Whiteside and Lynam, 2001). Previous studies have demonstrated an association between some of these dimensions of impulsivity and PTSD (Aidman and Kollaras-Mitsinikos, 2006; Joseph et al., 1997; Kotler et al., 2001; Oquendo et al., 2005). For example, Kotler et al. (2001) reported that individuals with PTSD (vs. individuals with other anxiety disorders and matched controls) exhibited significantly higher scores on a measure of impulsivity (Impulsivity Control Scale; Plutchik and van Praag, 1989) that assessed behaviors consistent with the impulsivity dimensions of (lack of) premeditation (i.e., spur of the moment behaviors) and (lack of) perseverance (i.e., lack of patience). Furthermore, Joseph et al. (1997) found that trauma-exposed individuals with heightened PTSD symptom severity (vs. those with lower levels of PTSD symptoms) exhibited greater impulsivity, as assessed by the Impulsiveness subscale of the Eysenck Impulsiveness Questionnaire (Eysenck and Eysenck, 1978) which examines behaviors consistent with the impulsivity dimension of (lack of) premeditation.

Despite preliminary evidence for an association between PTSD and certain facets of impulsivity, studies examining the precise nature and direction of this association are limited. Consequently, it is not clear if impulsivity contributes to PTSD, PTSD leads to greater impulsivity, or both. For example, there is evidence that impulsivity may increase risk for traumatic exposure (Jang et al., 2003), contributing to the development (and, in the case of repeated traumatic exposure, exacerbation) of PTSD symptoms (see Cottler et al., 1992). However, it also possible that particular symptoms of PTSD (e.g., hyperarousal and re-experiencing symptoms) may deplete self-regulatory resources (see Baumeister, 2003), limiting resources available to control impulsive behaviors. Indeed, evidence suggests that symptoms of hyperarousal (e.g., sleep difficulties, irritability) are positively associated with impulsivity (Medeiros et al., 2005; Stanford et al., 1995). Furthermore, several models of impulsivity posit (directly or indirectly) a relationship between impulsivity and arousal (Barratt and Patton, 1983; Eysenck and Eysenck, 1985), suggesting that the heightened physiological arousal observed among individuals with PTSD (e.g., Gerardi et al., 1994) may contribute to the impulsivity observed within this population (Joseph et al., 1997).

Although no studies have examined facets of impulsivity among individuals with cooccurring PTSD-SUD, literature suggests that impulsivity may be particularly elevated among individuals with a SUD and co-occurring PTSD. Theoretical literature highlights the likely bi-directional nature of the SUD-impulsivity relation, with substance abuse posited to be both a risk factor for and consequence of impulsivity (Hirschtritt et al., 2012). Moreover, 
research provides strong support for a robust association between facets of impulsivity and SUDs in general. For example, individuals with a SUD have been found to discount the value of delayed rewards (choosing smaller immediate rewards over larger delayed rewards; Madden et al., 1997) and fail to inhibit extraneous responding (Fillmore and Rush, 2002). Likewise, SUD patients have been found to exhibit significantly higher levels of several facets of impulsivity than non-SUD controls, including negative urgency, lack of premeditation, and lack of perseverance (Verdejo-García et al., 2007). Finally, Lejuez et al. (2007) found multiple aspects of impulsivity to be significantly positively correlated with cocaine dependence and past year cocaine use among SUD patients.

The goal of this study was to extend extant research by (a) examining differences in emotion dysregulation and impulsivity (assessed as multi-faceted constructs) between SUD patients with (vs. without) current PTSD, and (b) exploring the unique contributions of emotion dysregulation and impulsivity dimensions to PTSD within this population. Consistent with past findings of an association between PTSD and most of the impulsivity and emotion dysregulation dimensions examined here (e.g., Joseph et al., 1997; Kotler et al., 2001; McDermott et al., 2009), we hypothesized that SUD patients with (vs. without) current PTSD would report greater emotion dysregulation (overall and across all specific dimensions other than lack of emotional awareness) and higher levels of all four facets of impulsivity. Given the absence of research examining the unique contributions of impulsivity and emotion dysregulation to PTSD among SUD patients and the limited theoretical literature with regard to the convergence and divergence of the impulsivity and emotion dysregulation constructs (which are considered distinct yet overlapping constructs; Schreiber et al., 2012), no a priori hypotheses were made regarding the unique associations between emotion dysregulation and impulsivity dimensions and PTSD.

\section{Method}

\subsection{Participants}

Participants were 205 SUD patients consecutively admitted to a residential SUD treatment facility in Mississippi. In terms of racial/ethnic background, 56\% of participants selfidentified as White, $36 \%$ as Black/African American, $4 \%$ as Native American, $2 \%$ as Latino/Latina, and $2 \%$ as "other." See Table 1 for additional demographic characteristics of this sample.

\subsection{Measures}

2.2.1. Clinical Interviews-The Clinician-Administered PTSD Scale (CAPS; Blake et al., 1990) was used to assess for current PTSD. We chose to use the CAPS to assess PTSD because of its advantages over the Structured Clinical Interview for DSM-IV Axis I Disorders (SCID-IV; First et al., 1996). With regard to the assessment of PTSD, the SCIDIV lacks explicit rating descriptors, provides primarily dichotomous information, and does not assess different components of PTSD symptom severity (Blake et al., 1995). The CAPS, on the other hand, is a structured diagnostic interview that treats PTSD symptom severity as a multidimensional construct. Specifically, the CAPS assesses the frequency and intensity of all 17 DSM-IV PTSD symptoms. Frequency items are rated from 0 (never or none/not at all) to 4 (daily or almost every day or more than $80 \%$ ). Intensity items are rated from 0 (none) to 4 (extreme). The CAPS has adequate interrater reliability, internal consistency, and convergent validity with the SCID-IV and other established measures of PTSD (Weathers et al., 2001). We utilized the Item Severity $\geq 4$ rule, which requires that at least one reexperiencing, three avoidance, and two hyperarousal symptoms have a severity rating (frequency + intensity) of $\geq 4$ to establish PTSD. 
The SCID-IV was used to assess for current Axis I disorders (with the exception of PTSD). Given evidence for an association between both emotion dysregulation and impulsivity and a variety of Axis I disorders (see Gratz and Tull, 2010; Whiteside and Lynam, 2001), the number and presence of co-occurring current substance use, mood, and anxiety disorders were examined as potential covariates.

All interviews were administered by post-baccalaureate or doctoral-level clinical assessors trained by the principal investigator (MTT). All interviews were reviewed by a PhD level clinician (MTT or KLG), with diagnoses confirmed in consensus meetings. The collaborative, iterative process used to reach final diagnoses precludes calculation of reliability coefficients for SCID-IV and CAPS diagnoses. Despite this limitation, it is important to note that diagnostic discrepancies were found in $<5 \%$ of cases (overall agreement was approximately $95 \%)$.

2.2.2. Measure of Emotion Dysregulation-The Difficulties in Emotion Regulation Scale (DERS; Gratz and Roemer, 2004) is a 36-item self-report measure that assesses individuals' typical levels of emotion dysregulation across six domains: nonacceptance of negative emotions, difficulties engaging in goal-directed behaviors when distressed, difficulties controlling impulsive behaviors when distressed, limited access to emotion regulation strategies perceived as effective, lack of emotional awareness, and lack of emotional clarity. The DERS has been found to demonstrate good test-retest reliability and adequate construct and predictive validity (Gratz and Roemer, 2004; Gratz and Tull, 2010). Items were recoded so that higher scores indicate greater emotion dysregulation, and a sum was calculated. Internal consistency in this sample was good for the total score $(\alpha=.89)$ and adequate for all subscales (as=.76-.87).

2.2.3. Measure of Impulsivity-The UPPS Impulsive Behavior Scale (UPPS; Whiteside et al., 2005) is a 45-item self-report measure that assesses four distinct facets of impulsivity: (lack of) perseverance, negative urgency, (lack of) premeditation, and sensation seeking. Participants rate the extent to which each item applies to them on a 4-point Likert-type scale (1=rarely/never true, $4=$ almost always/always true). Scores are provided for each of the four dimensions of impulsivity. The four scales have been found to have good convergent validity and good discriminant validity from each other (Cyders and Smith, 2007; Smith et al., 2007). Internal consistency in this sample was adequate to good (as=.79-.92).

\subsection{Procedure}

All procedures were reviewed and approved by the University of Mississippi Medical Center's Institutional Review Board. Data were collected as part of a larger study examining predictors of residential SUD treatment dropout. To be included in the study, participants were required to have (a) obtained a Mini-Mental Status Exam (Folstein et al., 1975) score of $\geq 24$; and (b) exhibited no current psychotic disorders (per the SCID-IV). Eligible participants were recruited for this study no sooner than 72 hours after entry in the facility. Those who met inclusion criteria were provided with information about study procedures and associated risks, following which written informed consent was obtained. All patients participated in this study within their first two weeks of treatment.

The study took part in two sessions conducted on separate days. In the first session, participants were interviewed with the SCID-IV and CAPS. In the second session, participants completed a battery of questionnaires that included the UPPS and DERS. Participants received $\$ 15$ for each session. 


\section{RESULTS}

\subsection{Preliminary Analyses}

According to the CAPS, 28\% ( $n=58$ ) of participants met criteria for current PTSD. A series of independent sample t-tests and chi-square analyses were conducted to explore the impact of demographic factors and the severity of current psychopathology in general (i.e., number of co-occurring mood disorders, anxiety disorders [with the exception of PTSD], and SUDs) on PTSD status in order to identify potential covariates for the analysis examining the unique contributions of impulsivity and emotion dysregulation to PTSD status (see Table 1). Given the small number of participants in several of the income, marital status, education, and racial/ethnic categories, these variables were collapsed into dichotomous variables of over $(52 \%)$ versus under $(48 \%) \$ 10,000$ per year; single $(70 \%)$ versus in a committed relationship/married (30\%); high school diploma or less (62\%) versus education beyond high school (38\%); and White (56\%) versus Non-White (44\%). No differences in most demographic variables emerged as a function of PTSD status (see Table 1). However, women exhibited significantly higher rates of PTSD than men. Furthermore, the number and presence of co-occurring current mood and anxiety disorders was significantly greater among SUD patients with (vs. without) PTSD.

\subsection{Primary Analyses}

Multivariate analyses of covariance (MANCOVAs) were first conducted to examine between-group (PTSD vs. non-PTSD) differences in the dimensions of impulsivity and emotion dysregulation (controlling for the number of co-occurring substance use, mood, and anxiety disorders). With regard to the impulsivity dimensions, SUD patients with (vs. without) a current PTSD diagnosis were found to report significantly higher levels of negative urgency and significantly lower levels of sensation seeking. No significant group differences were found for lack of premeditation or lack of perseverance (see Table 2). With regard to differences in emotion dysregulation, SUD patients with (vs. without) PTSD reported significantly greater emotion dysregulation overall and across all specific dimensions of emotion dysregulation with the exception of lack of emotional awareness (see Table 2).

Analyses were also conducted with each separate mood and anxiety disorder entered as a covariate. MANCOVA results did not change (impulsivity Wilks' Lambda $=.94$, $F[4,194]=3.17, p<.05$, and emotion dysregulation Wilks' Lambda $=.87, F[7,191]=4.00, p<$. $001)$, with the exception of difficulties engaging in goal-directed behaviors when distressed $(F 1,197]=3.68, p=.06)$ and lack of emotional clarity $(F[1,197]=0.90, p=.34)$ which were found to no longer be significant.

Next, to identify unique associations between specific impulsivity dimensions and emotion dysregulation and current PTSD, a logistic regression analysis was conducted with PTSD status serving as the dependent variable. Impulsivity dimensions associated with PTSD at a univariate level (i.e., negative urgency and sensation seeking) and overall emotion dysregulation were entered simultaneously as independent variables. Specifically, given (a) the theoretical relevance of overall emotion dysregulation to PTSD (Tull et al., 2007); (b) past research highlighting the unique contribution of overall emotion dysregulation to PTSD, above and beyond other putative mechanisms (McDermott et al., 2009); (c) strong empirical and theoretical support for using the overall DERS score (unlike the UPPS, which does not generate a total score; Gratz and Tull, 2010); and (d) findings of strong intercorrelations between the DERS subscales within both nonclinical (e.g., Gratz and Roemer, 2004) and clinical (e.g., McDermott et al., 2009) samples, we included the overall emotion dysregulation score (vs. separate subscale scores) in the logistic regression model. 
The overall model accounted for $23 \%$ of the variance in PTSD status and correctly classified $29 \%$ of PTSD participants and 93\% of non-PTSD participants (with an overall correct classification rate of $75 \%$ ). Emotion dysregulation emerged as a reliable predictor of PTSD status $(\beta=.03, S E=.01, \mathrm{OR}=1.03$, Wald=14.16, $p<.001,95 \% \mathrm{CI}=1.02-1.05)$, accounting for unique variance in PTSD status above and beyond that associated with negative urgency $(\beta=.02, S E=.03, \mathrm{OR}=1.02$, Wald $=0.40, p>.05,95 \% \mathrm{CI}=0.97-1.07)$ and sensation seeking ( $\beta=-.05, S E=.02, \mathrm{OR}=0.95$, Wald=6.62, $p=.01,95 \% \mathrm{CI}=0.91-0.99$ ). (Given findings of a strong correlation between the emotion dysregulation dimension of difficulties controlling impulsive behaviors when distressed (DERS-IMPULSE) and the UPPS negative urgency subscale $(r=.64, p<.001)$, as well as theoretical evidence suggesting that these subscales measure similar constructs (Cyders and Smith, 2008), analyses were also conducted with the DERS-IMPULSE items removed from the overall DERS score. Results remained the same (in direction and level of significance) when the DERS-IMPULSE items were removed from the DERS score.)

Findings did not change when controlling for gender and number of mood and anxiety disorders. The final model including the covariates accounted for $36 \%$ of the variance in PTSD status and correctly classified $48 \%$ of PTSD participants and $92 \%$ of non-PTSD participants (with an overall correct classification rate of $80 \%$ ). Further, both sensation seeking $(p<.05)$ and overall emotion dysregulation $(p<.01)$ remained reliable unique predictors of PTSD status with the covariates in the model (see Table 3). Finally, we reran analyses with each separate mood and anxiety disorder associated with PTSD (see Table 1) entered in the first step of the regression analysis (vs. the summed scores representing total number of mood and anxiety disorders). Results did not change. Sensation seeking ( $\beta=-.05$, $S E=.02, \mathrm{OR}=0.95$, Wald $=4.70, p=.03,95 \% \mathrm{CI}=0.91-1.00)$ and overall emotion dysregulation $(\beta=.03, S E=.01, \mathrm{OR}=1.03$, Wald $=7.89, p=.005,95 \% \mathrm{CI}=1.01-1.05)$ remained reliable unique predictors of PTSD status above and beyond each separate mood and anxiety disorder associated with PTSD in this sample.

\section{DISCUSSION}

Consistent with previous literature (Ehring and Quack, 2010; McDermott et al., 2009; Tull et al., 2007), findings demonstrated that SUD patients with (vs. without) PTSD reported greater overall emotion dysregulation and the specific dimensions of lack of emotional acceptance, difficulties engaging in goal-directed behavior and controlling impulsive behaviors when distressed, lack of access to effective emotion regulation strategies, and lack of emotional clarity. Results also extend extant literature by demonstrating that emotion dysregulation contributes unique variance to co-occurring PTSD among SUD patients when accounting for the number of mood and other anxiety disorders (or separate mood and anxiety disorders found to be associated with PTSD) and trait impulsivity. Findings are consistent with theoretical literature highlighting the role of emotion dysregulation in PTSD (Cloitre, 1998) and highlight potential targets for the treatment of PTSD among SUD patients. Specifically, SUD patients with PTSD may benefit from learning more adaptive ways of responding to their emotions. For example, the process of mindfully observing emotions as they occur in the moment and labeling them objectively may promote emotional awareness and clarity. Similarly, learning to observe and describe internal and external experiences non-judgmentally may increase willingness to experience unpleasant emotions and decrease secondary emotional reactions to such emotions. Additionally, the process of mindfully observing emotions and associated action urges may help clients view emotions and behaviors as separate from one another, facilitating behavioral control in the context of emotional distress (for a review, see Gratz and Tull, 2010). 
Results also speak to the complex association between PTSD and impulsivity, providing evidence for higher levels of negative urgency and lower levels of sensation seeking among SUD patients with (vs. without) PTSD. Although the finding of lower sensation seeking among patients with PTSD is contrary to hypotheses, it is not without support in the literature (Solomon et al., 1995). For example, research suggests that individuals high in sensation seeking are better able to adjust to stressful situations and report lower levels of PTSD and other psychiatric symptoms following exposure to stressful events (i.e., a pretraumatic factor; Solomon et al., 1995). Furthermore, findings of a negative association between sensation seeking and PTSD are consistent with literature emphasizing the central role of avoidance in PTSD (Foa et al., 1989; Salters-Pedneault et al., 2004). Although the PTSD avoidance criteria describe the avoidance of stimuli associated with the traumatic event, there is evidence to suggest that individuals with PTSD may also be motivated to avoid other activities that bring about increased arousal. For instance, individuals with PTSD exhibit high levels of anxiety sensitivity (Taylor et al., 1992) which, in turn, may prompt the avoidance of not just traumatic memories and cues, but any arousal-inducing experience. Thus, the avoidance that accompanies PTSD may inhibit sensation seeking tendencies. Providing support for the robust nature of this association, sensation seeking was the only facet of impulsivity to remain uniquely associated with PTSD when controlling for emotion dysregulation and other relevant covariates. Together, these findings suggest a more complex association between impulsivity and PTSD than hypothesized, with the strength and direction of this association varying across different impulsivity domains.

Our finding of higher levels of negative urgency among patients with (vs. without) PTSD is consistent with past findings of heightened rates of impulsive behaviors among individuals with PTSD (e.g., McDevitt-Murphy et al., 2009) and suggests the utility of teaching SUD patients with PTSD skills for tolerating extreme emotional states without immediate action. For example, distress tolerance skills (most notably found in dialectical behavior therapy [DBT]; Linehan, 1993) may reduce engagement in rash actions by enabling the patient to focus on engaging in more adaptive actions. Likewise, the Seeking Safety (Najavits, 2002) skills of grounding and "red and green flags" (i.e., identifying signs of danger and safety for PTSD and substance abuse) may assist patients in persisting through intense negative emotions, as well as identify and manage high-risk situations for impulsive behaviors. Furthermore, mindfulness skills focused on observing and describing emotions and participating in present moment activities even in the context of distress, may help patients maintain goal-directed behavior in the context of negative affect.

Interestingly, and contrary to hypotheses and past research (Joseph et al., 1997), findings did not reveal a significant association between PTSD and the impulsivity facets of lack of premeditation and perseverance, suggesting that PTSD-SUD patients do not differ from their non-PTSD counterparts in the tendency to reflect on the consequences of behaviors before acting or persisting in goal-directed behaviors despite boredom and/or fatigue. Overall, findings suggest that although patients with PTSD may reflect on the consequences of their behaviors in general, they may not do so when experiencing extreme negative affect, or may simply discount the negative consequences of these behaviors in those moments (in favor of immediate positive consequences, such as emotional relief). Future studies investigating the effect of decision-making under different affective states among PTSD-SUD patients are needed.

In evaluating the implications of our findings, it is important to take into account several limitations. First, the cross-sectional and correlational nature of the data precludes determination of the precise nature and direction of the relationships examined here. Prospective, longitudinal investigations of the relationships examined here are needed. It will also be important to examine more complex models that explore the moderating and/or 
mediating role of emotion dysregulation and impulsivity domains in PTSD among SUD patients. A second limitation is the exclusive reliance on a self-report measure of emotion dysregulation, responses to which may be influenced by an individual's willingness and/or ability to report accurately on emotional responses. Future studies would benefit from the use of non-self-report (e.g., behavioral, physiological) measures of emotion dysregulation. Third, our findings may not generalize to other SUD populations or non-SUD clinical populations. Research should also examine the moderating role of SUD treatment status and level of care in the associations between co-occurring PTSD and both emotion dysregulation and impulsivity dimensions.

Despite limitations, results highlight the importance of examining whether PTSD-SUD patients may benefit from empirically-supported treatments that have been demonstrated to reduce PTSD symptoms and emotion dysregulation, such as DBT (Steil et al., 2011) and Skills Training in Affect and Interpersonal Regulation/Prolonged Exposure (Cloitre et al., 2002). Although empirically-supported treatments for PTSD-SUD patients are available (Seeking Safety [Najavits et al., 1998] and Concurrent Treatment of PTSD and Cocaine Dependence [Brady et al., 2004b]), they do not directly target emotion dysregulation. It will be important to examine the extent to which these treatments address emotion dysregulation among PTSD-SUD patients and whether outcomes for these treatments can be improved through by incorporating emotion regulation skills training.

\section{Acknowledgments}

The authors would also like to thank Michael McDermott, Melissa Soenke, Rachel Brooks, and Sarah Anne Moore for their assistance with data collection.

Role of the Funding Source

This study was funded by R21 DA022383 of the National Institute on Drug Abuse of the National Institutes of Health, awarded to the second author (MTT). The NIDA had no further role in study design; in the collection, analysis and interpretation of data; in the writing of the report; or in the decision to submit the paper for publication.

\section{REFERENCES}

Aidman E, Kollaras-Mitsinikos L. Personality dispositions in the prediction of posttraumatic stress reactions. Psychol. Rep. 2006; 99:569-580. [PubMed: 17153828]

Allen T, Moeller F, Rhoades H, Cherek D. Impulsivity and history of drug dependence. Drug Alcohol Depend. 1998; 50:137-145. [PubMed: 9649965]

American Psychiatric Association. Diagnostic and Statistical Manual of Mental Disorders. 4th ed., text revision. APA; Washington, DC: 2000.

Baker TB, Piper ME, McCarthy DE, Majeskie MR, Fiore MC. Addiction motivation reformulated: an affective processing model of negative reinforcement. Psychol. Rev. 2004; 111:33-51. [PubMed: 14756584]

Barratt, ES.; Patton, JH. Impulsivity: cognitive, behavioral, and psychophysiological correlate.. In: Zuckerman, M., editor. Biological Basis of Sensation Seeking, Impulsivity, and Anxiety. Lawrence Erlbaum Associates; Hillside, NJ: 1983. p. 77-122.

Baumeister RF. Ego depletion and self-regulation failure: a resource model of self-control. Alcohol. Clin. Exp. Res. 2003; 27:281-284. [PubMed: 12605077]

Blake DD, Weathers FW, Nagy L, Kaloupek DG, Gusman FD, Charney DS, Keane TM. The development of the clinician-administered PTSD scale. J. Trauma Stress. 1995; 8:75-90. [PubMed: 7712061]

Blake, DD.; Weathers, FW.; Nagy, L.; Kaloupek, DG.; Klauminzer, G.; Charney, DS.; Keane, TM. The Clinician Administered PTSD Scale. National Center for PTSD- Behavioral Science Division; Boston, MA: 1990. 
Brady KT. Comorbid posttraumatic stress disorder and substance use disorders. Psychiatr. Ann. 2001; 31:313-319.

Brady K, Back S, Coffey S. Substance abuse and posttraumatic stress disorder. Curr. Dir. Psychol. Sci. 2004a; 13:206-209.

Brady KT, Danksy BS, Back SE, Foa EB, Carroll KM. Exposure therapy in the treatment of PTSD among cocaine-dependent individuals: preliminary findings. J. Subst. Abuse Treat. 2004b; 21:4754. [PubMed: 11516926]

Cloitre, M. Sexual revictimization: risk factors and prevention.. In: Follette, VM.; Ruzek, JI.; Abueg, FR., editors. Cognitive-Behavioral Therapies for Trauma. Guilford Press; New York: 1998. p. 278-304.

Cloitre M, Koenen KC, Cohen LR, Han H. Skills training in affective and interpersonal regulation followed by exposure: a phase-based treatment for PTSD related to childhood abuse. J. Consult. Clin. Psychol. 2002; 70:1067-1074. [PubMed: 12362957]

Cloninger CR, Svrakic DM, Przybeck TR. A psychobiological model of temperament and character. Arch. Gen. Psychiatry. 1993; 50:975-990. [PubMed: 8250684]

Cottler L, Compton W, Mager D, Spitznagel E. Posttraumatic stress disorder among substance users from the general population. Am. J. Psychiatry. 1992; 149:664-670. [PubMed: 1575258]

Cyders MA, Smith GT. Mood-based rash action and its components: positive and negative urgency. Pers. Individ. Dif. 2007; 43:839-850.

Cyders MA, Smith GT. Emotion-based dispositions to rash action: positive and negative urgency. Psychol. Bull. 2008; 134:807-828. [PubMed: 18954158]

Ehring T, Quack D. Emotion regulation difficulties in trauma survivors: the role of trauma type and PTSD symptom severity. Behav. Ther. 2010; 41:587-598. [PubMed: 21035621]

Eysenck, HJ.; Eysenck, MW. Personality and Individual Differences: A Natural Science Approach. Plenum Press; New York: 1985.

Eysenck SB, Eysenck HJ. The place of impulsiveness in a dimensional system of personality description. Br. J. Soc. Clin. Psychol. 1977; 16:57-68. [PubMed: 843784]

Eysenck SB, Eysenck HJ. Impulsiveness and venturesomeness: their position in a dimensional system of personality description. Psychol. Rep. 1978; 43:1247-1255. [PubMed: 746091]

Fillmore MT, Rush CR. Impaired inhibitory control in chronic cocaine abusers. Drug Alcohol Depend. 2002; 66:265-273. [PubMed: 12062461]

First, MB.; Spitzer, RL.; Gibbon, M.; Williams, JBW. Structured Clinical Interview for DSM-IV Axis I Disorders - Patient Edition. New York State Psychiatric Institute; New York, NY: 1996.

Foa EB, Kozak MJ. Emotional processing of fear: exposure to corrective information. Psychol. Bull. 1986; 99:20-35. [PubMed: 2871574]

Folstein MF, Folstein SE, McHugh PR. Mini-mental state: a practical method for grading the cognitive state of patients for the clinician. J. Psychiatr. Res. 1975; 12:189-198. [PubMed: 1202204]

Ford JD, Hawke J, Alessi S, Ledgerwood D, Petry N. Psychological trauma and PTSD symptoms as predictors of substance dependence treatment outcomes. Behav. Res. Ther. 2007; 45:2417-2431. [PubMed: 17531193]

Fox H, Axelrod S, Paliwal P, Sleeper J, Sinha R. Difficulties in emotion regulation and impulse control during cocaine abstinence. Drug Alcohol Depend. 2007; 89:298-301. [PubMed: 17276626]

Fox H, Hong K, Sinha R. Difficulties in emotion regulation and impulse control in recently abstinent alcoholics compared with social drinkers. Addict. Behav. 2008; 33:388-394. [PubMed: 18023295]

Gerardi RJ, Keane TM, Cahoon BJ, Klauminzer GW. An in vivo assessment of physiological arousal in posttraumatic stress disorder. J. Abnorm. Psychol. 1994; 103:825-827. [PubMed: 7822586]

Gratz KL, Roemer L. Multidimensional assessment of emotion regulation and dysregulation: development, factor structure, and initial validation of the difficulties in emotion regulation scale. J. Psychopathol. Behav. Assess. 2004; 26:41-55.

Gratz, KL.; Tull, MT. Emotion regulation as a mechanism of change in acceptance-and mindfulnessbased treatments.. In: Baer, RA., editor. Assessing Mindfulness and Acceptance: Illuminating the Processes of Change. New Harbinger Publications; Oakland, CA: 2010. p. 105-133. 
Hayes SC, Wilson KG, Gifford EV, Follette VM, Strosahl K. Experiential avoidance and behavioral disorders: a functional dimensional approach to diagnosis and treatment. J. Consult. Clin. Psychol. 1996; 64:1152-1168. [PubMed: 8991302]

Hien DA, Nunes E, Levin FR, Fraser D. Posttraumatic stress disorder and short-term outcome in early methadone treatment. J. Subst. Abuse Treat. 2000; 19:31-37. [PubMed: 10867298]

Hirschtritt, ME.; Potenza, MN.; Mayes, LC. Impulsivity and co-occurring psychiatric disorders.. In: Grant, JE.; Potenza, MN., editors. The Oxford Handbook of Impulse Control Disorders. Oxford University Press; Oxford, England: 2012. p. 80-93.

Jang KL, Stein MB, Taylor S, Asmundson GJG, Livesley WJ. Exposure to traumatic events and experiences: aetiological relationships with personality function. Psychiatry. Res. 2003; 120:6169. [PubMed: 14500115]

Joseph S, Dalgleish T, Thrasher S, Yule W. Impulsivity and post-traumatic stress. Pers. Individ. Dif. 1997; 22:279-281.

Kessler RC, Berglund PA, Demler O, Jin R, Merikangas KR, Walters EE. Lifetime prevalence and age-of-onset distributions of DSM-IV disorders in the National Comorbidity Survey Replication (NCS-R). Arch. Gen. Psychiatry. 2005; 62:593-602. [PubMed: 15939837]

Kotler M, Iancu I, Efroni R, Amir M. Anger, impulsivity, social support, and suicide risk in patients with posttraumatic stress disorder. J. Nerv. Ment. Dis. 2001; 189:162-167. [PubMed: 11277352]

Lejuez CW, Bornovalova MA, Reynolds EK, Daughters SB, Curtin JJ. Risk factors in the relationship between gender and crack/cocaine. Exp. Clin. Psychopharmacol. 2007; 15:165-175. [PubMed: 17469940]

Linehan, MM. Cognitive Behavioral Treatment of Borderline Personality Disorder. Guilford Press; New York, NY: 1993.

Madden GJ, Petry NM, Badger GJ, Bickel WK. Impulsive and self-control choices in opioiddependent patients and non-drug-using control patients: drug and monetary rewards. Exp. Clin. Psychopharmacol. 1997; 5:256-262. [PubMed: 9260073]

McDermott MJ, Tull MT, Gratz KL, Daughters SB, Lejuez CW. The role of anxiety sensitivity and difficulties in emotion regulation in posttraumatic stress disorder among crack/cocaine dependent patients in residential substance abuse treatment. J. Anxiety. Disord. 2009; 23:591-599. [PubMed: 19233609]

McDevitt-Murphy ME, Parra GR, Shea M, Yen S, Grilo CM, Sanislow CA, McGlashan TH, Gunderson JG, Skodol AE. Trajectories of PTSD and substance use disorders in a longitudinal study of personality disorders. Psychol. Trauma. 2009; 1:269-281.

Medeiros M, Carvalho LBC, Silva TA, Prado LBF, Prado GF. Sleep disorders are associated with impulsivity in school children aged 8 to 10 years. Arquivos de Neuro-Psiquiatria. 2005; 63:761765. [PubMed: 16258652]

Moeller F, Dougherty D. Impulsivity and substance abuse: what is the connection?. Addict. Disord. Their Treat. 2002; 1:3-10.

Najavits, L. Seeking Safety: A Treatment Manual for PTSD and Substance Abuse. Guilford Press; New York, NY: 2002.

Najavits L, Harned M, Gallop R, Butler S, Barber J, Thase M, Crits-Christoph P. Six-month treatment outcomes of cocaine-dependent patients with and without PTSD in a multisite national trial. J. Stud. Alcohol Drugs. 2007; 68:353-361. [PubMed: 17446974]

Najavits LM, Weiss RD, Shaw SR, Muenz LR. "Seeking safety": outcome of a new cognitivebehavioral psychotherapy for women with posttraumatic stress disorder and substance dependence. J. Trauma Stress. 1998; 11:437-456. [PubMed: 9690186]

Oquendo M, Brent DA, Birmaher B, Greenhill L, Kolko D, Stanley B, Zelazny J, Burke AK, Firinciogullari S, Ellis SP, Mann JJ. Posttraumatic stress disorder comorbid with major depression: factors mediating the association with suicidal behavior. Am. J. Psychiatry. 2005; 162:560-566. [PubMed: 15741474]

Patton JH, Stanford MS, Barratt ES. Factor structure of the Barratt Impulsiveness Scale. J. Clin. Psychol. 1995; 51:768-774. [PubMed: 8778124] 
Plotzker R, Metzger D, Holmes W. Childhood sexual and physical abuse histories, PTSD, depression, and HIV risk outcomes in women injection drug users: a potential mediating pathway. Am. J. Addict. 2007; 16:431-438. [PubMed: 18058406]

Plutchik R, Van Praag H. The measurement of suicidality, aggressivity and impulsivity.Prog. Neuropsychopharmacol. Biol. Psychiatry. 1989; 13:S23-S34.

Salters-Pedneault K, Tull MT, Roemer L. The role of avoidance of emotional material in the anxiety disorders. Appl. Prev. Psychol. 2004; 11:95-114.

Schreiber LRN, Grant JE, Odlaug BL. Emotion regulation and impulsivity in young adults. J. Psychiatr. Res. 2012; 46:651-658. [PubMed: 22385661]

Smith G, Fischer S, Cyders M, Annus A, Spillane N, McCarthy D. On the validity and utility of discriminating among impulsivity-like traits. Assess. 2007; 14:155-170.

Solomon Z, Ginzburg K, Neria Y, Ohry A. Coping with war captivity: the role of sensation seeking. Eur. J. Pers. 1995; 9:57-70.

Stanford MS, Greve KW, Dickens TJ. Irritability and impulsivity: relationship to self-reported impulsive aggression. Pers. Individ. Dif. 1995; 19:757-760.

Steil R, Dyser A, Priebe K, Kleindienst N, Bohus M. Dialectical behavior therapy for posttraumatic stress disorder related to childhood sexual abuse: a pilot study of an intensive residential treatment program. J. Trauma Stress. 2011; 24:102-106. [PubMed: 21351167]

Taylor S, Koch WJ, McNally RJ. How does anxiety sensitivity vary across the anxiety disorders? J. Anxiety Disord. 1992; 6:249-259.

Tull MT, Barrett HM, McMillan ES, Roemer L. A preliminary investigation of the relationship between emotion regulation difficulties and posttraumatic stress symptoms. Behav. Ther. 2007; 38:303-313. [PubMed: 17697854]

Verdejo-García A, Bechara A, Recknor EC, Pérez-García M. Negative emotion-driven impulsivity predicts substance dependence problems. Drug Alcohol Depend. 2007; 91:213-219. [PubMed: 17629632]

Weathers F, Keane T, Davidson J. Clinician-administered PTSD Scale: a review of the first ten years of research. Depress. Anxiety. 2001; 13:132-156. [PubMed: 11387733]

Whiteside SP, Lynam DR. The Five Factor Model and impulsivity: using a structural model of personality to understand impulsivity. Pers. Individ. Dif. 2001; 30:669-689.

Whiteside SP, Lynam DR, Miller JD, Reynolds SK. Validation of the UPPS Impulsive Behaviour Scale: a four-factor model of impulsivity. Eur. J. Pers. 2005; 19:559-574. 
क

$\frac{\overline{0}}{\frac{0}{\circ}}$

$\stackrel{0}{\Xi}$

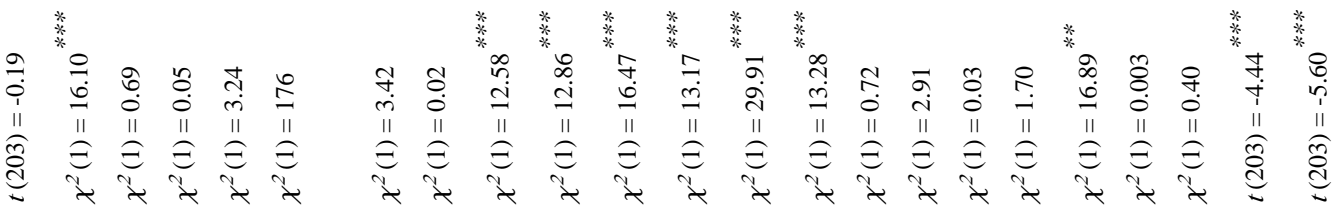

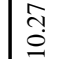

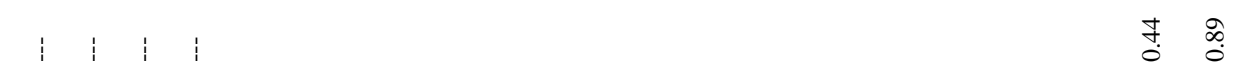

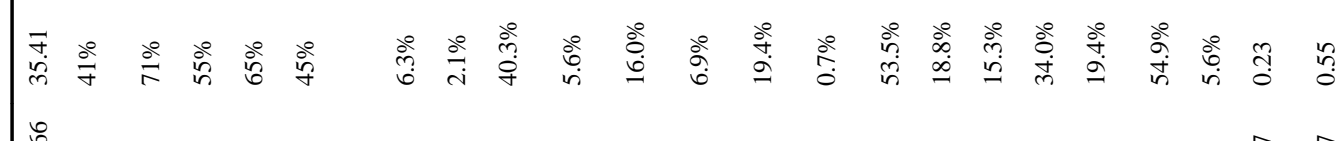
के की $\stackrel{0}{\varrho}: 1: 1$ in

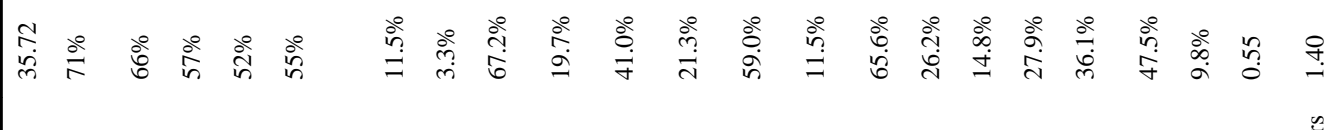




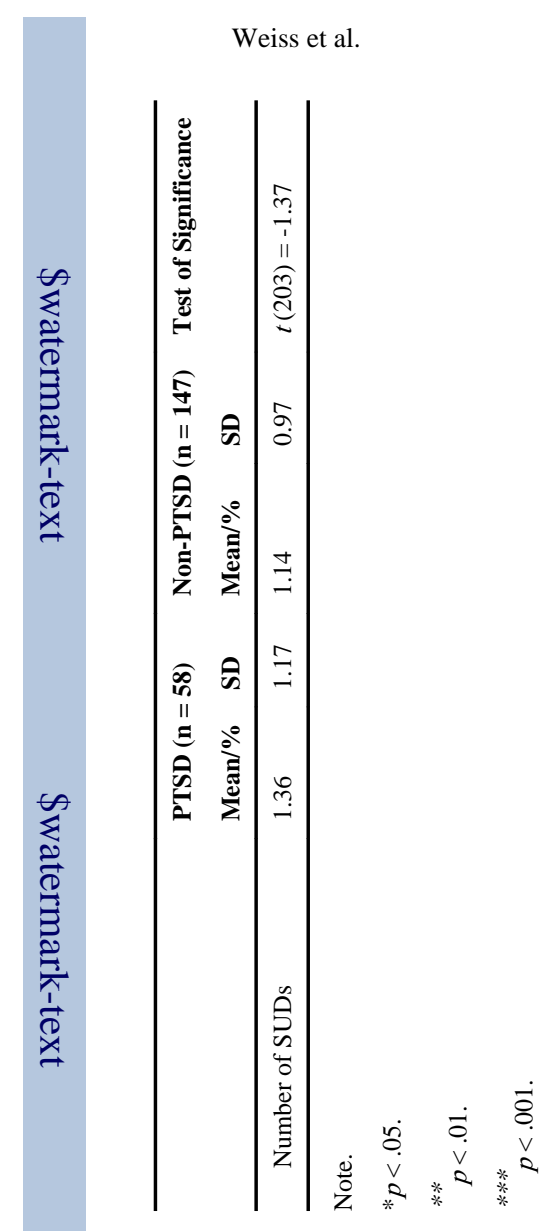

Page 14 


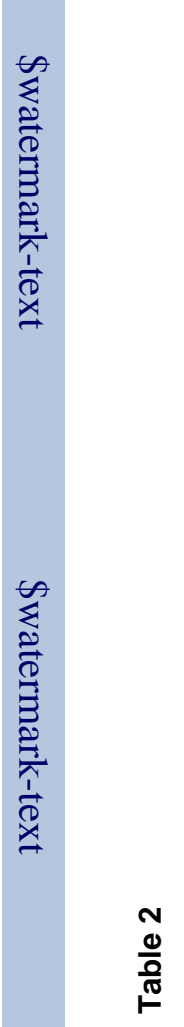

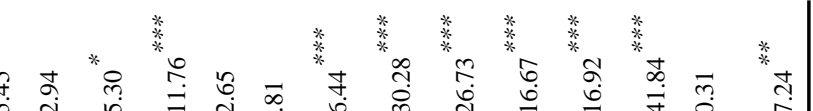
II II II

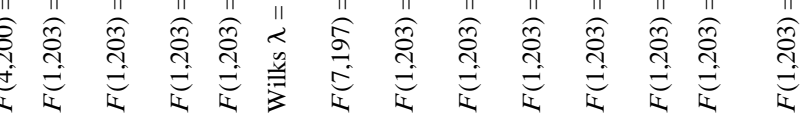

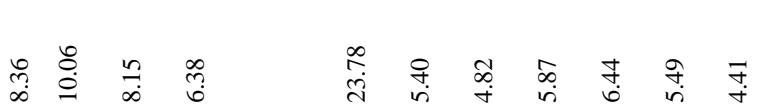

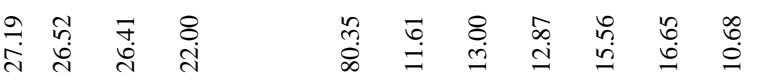

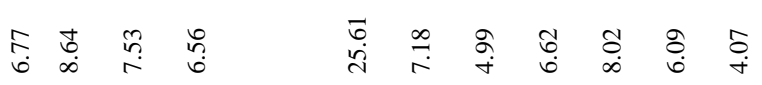

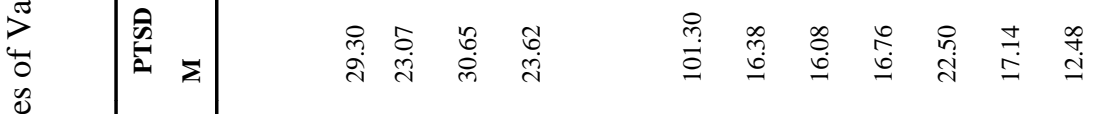




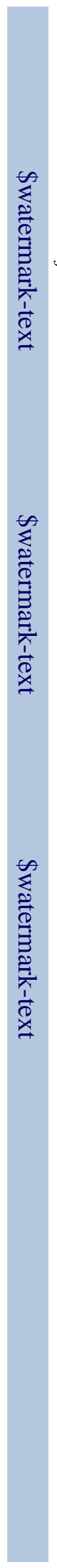

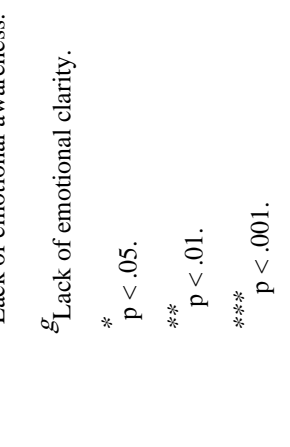




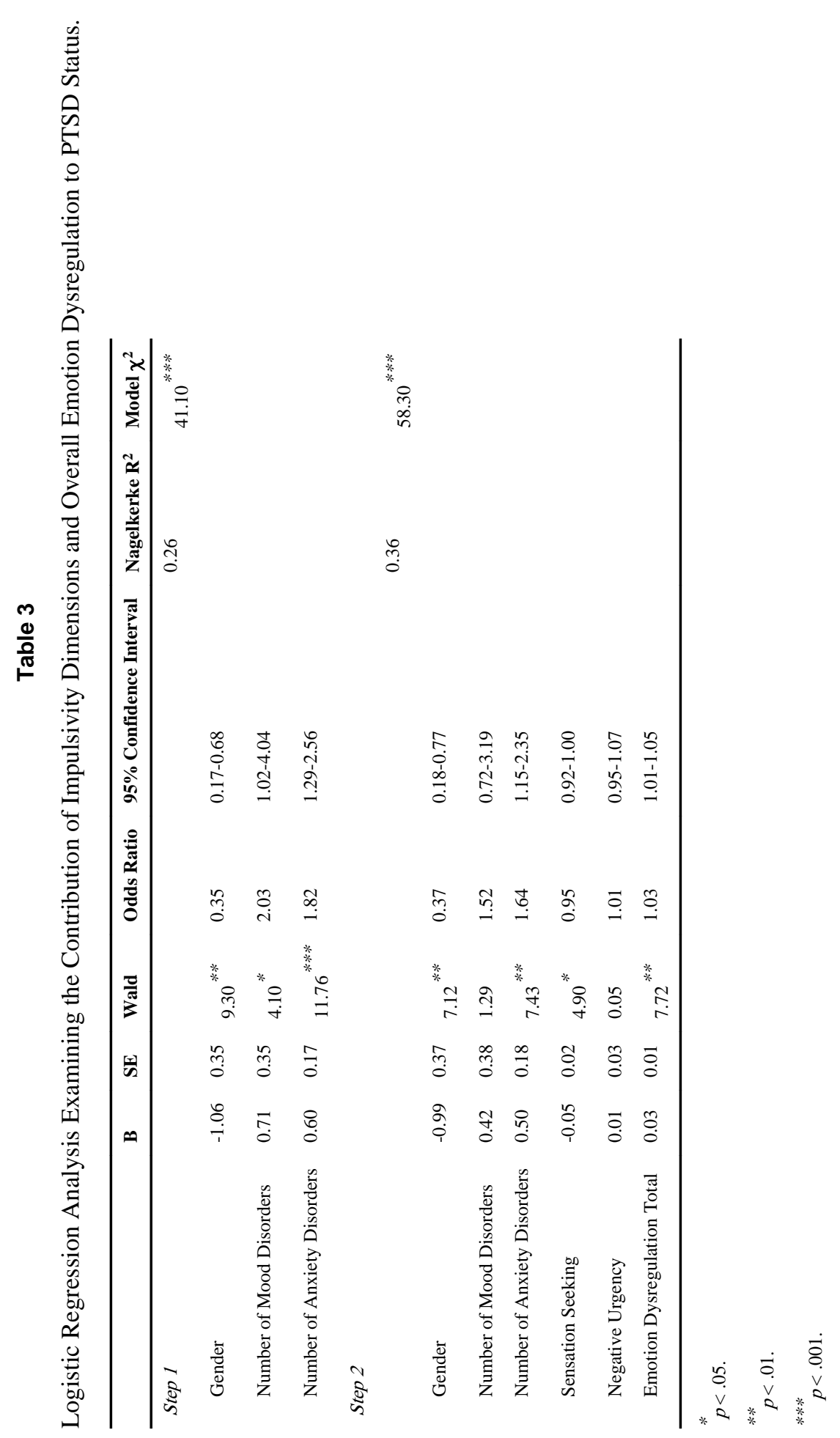

